\title{
What can be done about adolescent pregnancy in South Sudan?
}

\author{
Isaac Gawar \\ Paediatrician, South Sudan Paediatrics \\ Association, South Sudan
}

Correspondence:

Isaac Gawar

gawarisaac10@gmail.com

Submitted: May 2021

Accepted: July 2021

Published: August 2021

\section{Citation:}

Gawar. What can be done about adolescent pregnancy in South

Sudan? South Sudan Medical Journal 2021;14(3):89-93 (C) 2021 The Author (s) License: This is an open access article under CC BY-NC-ND DOI:

https://dx.doi.org/10.4314/ssmj.v14i3.5

\begin{abstract}
Introduction: The World Health Organization (WHO) defines 'adolescents' as individuals aged 10-19 years. The national family planning policy of South Sudan states that "by the age of 19 , one out of three girls is already married or in union; and the same proportion has already started childbearing". The causes of adolescent pregnancy can be attributed to social, cultural, political and health systems gaps.
\end{abstract}

Objective: This review article looks at the contributory factors for adolescent pregnancy in South Sudan, the effects of these pregnancies and describes some solutions and recommendations.

Method: A direct search was conducted in Google scholar and other search engines looking at titles such as teenage/adolescent pregnancy in South Sudan, adolescent pregnancy in Africa, effects of adolescent pregnancy, and interventions to combat teenage/adolescent pregnancy.

Results: The contributory factors for adolescent pregnancy in South Sudan are sociocultural where the need for dowries, forced and arranged marriages, gender based violence are examples, economic and political factors; where poor implementation or inadequate adolescent policies, illiteracy and poverty are major factors, failure of health systems; where the unavailability of health services such as the provision of contraceptives for adolescents and scarcity of teenager/adolescent-friendly health clinics; and individual factors where adolescents reported desire to be mothers, societal recognition and peer pressure. In addition to all of these, rape and sexual slavery are reported as causes of adolescent pregnancy.

Conclusions: Causes of adolescent pregnancy in South Sudan are multifactorial. The country needs to adopt the published guidelines from WHO on reduction of adolescent pregnancy and learn from experiences of countries that showed a greater reduction. The utilization of interventions made through research and evidence-based information which are suitable to South Sudan context are crucial.

Key words: Adolescent pregnancy, teenage pregnancy, review, contributory factors, recommendations, South Sudan

\section{Introduction}

The World Health Organization (WHO) defines 'adolescents' as individuals aged 10-19 years. ${ }^{[1]}$ It is estimated that approximately 12 million girls aged 1519 years and at least 777,000 girls aged under 15 years give birth each year in developing regions. ${ }^{[2]}$

Globally, babies born to adolescent girls constitute about $11 \%$ of all births, and $95 \%$ of these are found in developing countries. ${ }^{[3]}$ In Africa, the estimated prevalence of adolescent pregnancy is $18.8 \%$; a higher prevalence is observed in 
the East African sub-region (21.5\%) and the lowest is in the North Africa (9.2\%). ${ }^{[3]}$

The national family planning policy of South Sudan has stated that "by the age of 19 , one out of three girls is already married or in union; and the same proportion has already started childbearing". [4] South Sudan is among the top ten countries with the highest prevalence of adolescent pregnancy, the others being Burkina Faso, Central African Republic, Chad, Guinea, Malawi, Mali, Mozambique, Niger and Bangladesh. ${ }^{[5]}$ The prevalence of adolescent pregnancy can exceed $70 \% .{ }^{[6]}$ The causes can be attributed to social, cultural, political and health systems.

The aim of this review is to find contributory factors that are unique to South Sudan, to look at the effects of these pregnancies and to describe some solutions and recommendations. Adolescent pregnancy is a public health problem which has taken its legitimacy from the common norms, customs, and tribal rules of the South Sudanese communities. ${ }^{[4,5,6]}$

\section{Method}

A direct search was conducted in Google scholar and other search engines looking at titles such as teenage/adolescent pregnancy in South Sudan, adolescent pregnancy in Africa, effects of adolescent pregnancy, and interventions to combat teenage/adolescent pregnancy.

\section{Results}

\section{Why adolescent pregnancy is high in South Sudan}

Sociocultural factors play major role. In South Sudan these include the need for dowries, gender base violence, respect for tradition and norms of marriage, lack of parental care, and lack of communication and supervision (Figure 1). ${ }^{[4,5,6,7]}$

Additionally, poor implementation or inadequate adolescent policies, weak laws prohibiting forced marriage, widespread illiteracy among adolescent girls, lack of job opportunities, poor skills and poverty, and lack of food are amongst the economic and political factors associated

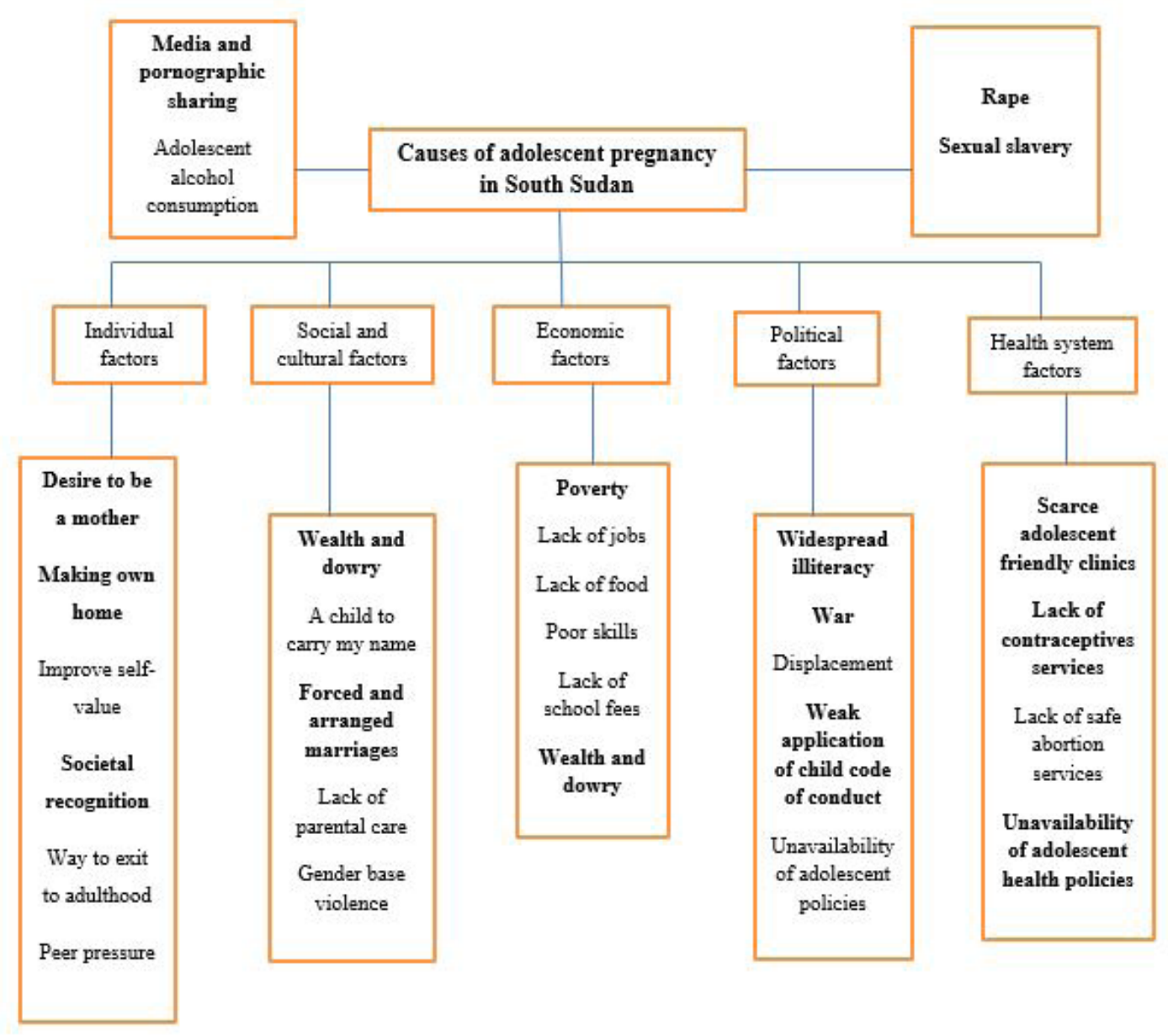

Figure 1. Determinants of adolescent pregnancy in South Sudan 
with this practice. ${ }^{[4,5,6,7]}$

Moreover, failure of, and the unavailability of health services, such as the provision of contraceptives for adolescents, psychosocial counselling and scarcity of teenager-friendly health clinics contribute to this problem.

The displacement of civilians during war time has accompanied issues such as rape and sexual slavery. Reluctance of adolescent girls to discuss their choices of sexual life and the presence of dysfunctional families are hindering the fight against adolescent pregnancy. ${ }^{[6,7]}$

Adolescents like to be respected and recognized by others; factors such as desire to be a mother, making their own home, improve self-value, societal recognition and peer pressure are examples of the individual factors. ${ }^{[4]}$ These factors are more prevalent in societies living in rural settings and lacking opportunities for girl education.

In Uganda, Manzi, et al found that the factors driving early adolescent pregnancy were a knowledge gap, poverty, influence from peer groups and incitement with gifts. ${ }^{[8]} \mathrm{A}$ study by Ochen et al in Lira, Uganda reported that early alcohol consumption, being married, lack of control over sex and peer pressure were significantly contributing to early adolescent pregnancy. ${ }^{[9]}$ In Kenya, contributory factors reported for early adolescent pregnancy were poverty, community customs on gender roles and the value of girls, violence, inability to access formal education, and societal isolation. ${ }^{[10]}$ Additionally, access to, and sharing of, pornographic media among adolescents can lead them to initiate sexual activities at an early age. ${ }^{[1]}$

\section{The effects of adolescent pregnancy}

Adolescent pregnancy leads to early school drop-out, divorce, rejection by parents, stigmatism, and sometimes if the baby is unwanted, abortion. ${ }^{[5]}$ Furthermore, adolescent girls who become pregnant or who have children are often reported to have been emotionally and sexually abused; their children have low birth weight, malnutrition and they lack mental well-being with high risk of mortality. ${ }^{[12]}$ Moreover, girls who have become pregnant through unprotected sex are at high risk of acquiring sexual transmitted diseases including HIV; these have substantial health risks to them and their babies. Adolescent pregnancy significantly contributes to maternal mortality and perinatal and infant mortality, and to the vicious cycle of ill-health and poverty. ${ }^{[13]}$

\section{Solutions}

Government sectors should collaborate with their national and international partners to bridge the gaps and to ensure appropriate and sustainable interventions to reduce adolescent pregnancy. A greater budget needs to be allocated to sectors involved with adolescent health.

The South Sudan constitution defines people aged less than 18 years as minors. This implies that teenage/ adolescent girls who are involved in sexual relations should be protected by law. Customary practices sometimes run contrary to an adolescent's rights, hindering her healthy choices and directly increasing the prevalence of early pregnancy. A debate with tribal leaders and chiefs in South Sudan is required to examine these issues and arrive at a consensus. ${ }^{[14]}$ Additionally, a review is essential with practical implementation of laws (e.g. South Sudan "Child Act, 2008") that are meant to protect the rights of children and adolescents.

Educating girls delays the age of early pregnancy. Schooling for girls needs to be prioritized, through provision of more resources and improved partnership between organizations. In addition, schools, churches, community gatherings and families should introduce child and adolescent sex education that is appropriate to their mental development and culturally sensitive. ${ }^{[15,16]}$

Prohibiting all forms of gender-based violence, including child-forced marriage through awareness programmes, reporting and establishing community-led initiatives, such as community protection committees, would help to combat this issue. ${ }^{[6]}$ Campaigns for activities that help to elevate women and girls from poverty, (such as marketing and productive skills) as well as the promotion of gender equity in job seeking, and creating gender-sensitive programmes which are directed towards vulnerable community groups (e.g. those in internal displaced camps, refugees, and families living on the street). Health Services such as adolescent-friendly clinics need to be established and integrated into primary health care, and contraceptive and counselling services should be made accessible. Provision of laws and policies integrating contraceptive and other health services are essential. ${ }^{[16,17,18,19]}$

WHO has produced a guideline to help low-income countries reduce early pregnancy and poor reproductive outcomes among adolescents. This identifies six interventions to address this practice and has provided an analytic framework for policy makers and programme managers with emphasis on utilizing the interventions that are suitable and individualized to a country's circumstances. ${ }^{[20]}$ These are: - preventing early marriage; - preventing early pregnancy through sexuality education; - increasing education opportunities and economic and social support programmes; - increasing the use of contraception; - reducing coerced sex; - preventing unsafe abortion; and increasing the use of prenatal care childbirth and postpartum care. ${ }^{[20,21]}$

The United Kingdom is an example where interventions since 2000 have reduced adolescent pregnancy by $62 \%$ and $65 \%$ for girls aged under 18 years and 16 years respectively. The illustrated interventions in the United Kingdom Teenage Pregnancy Prevention Framework 
includes targeted prevention for young people at risk; support for parents to discuss relationships and sexual health; relationships and sex education in schools and colleges; and support for pregnant teenagers and young parents. ${ }^{[22]}$ Public Health England acknowledges the need for multiple agencies to address early adolescent pregnancies and it states that "teenage pregnancy is more than a health issue" in that it involves socio-economic factors as well. ${ }^{[22]}$

\section{Recommendations for South Sudan}

- Develop policies for preventing adolescent pregnancy that are endorsed by the leadership of South Sudan Parliament and spearheaded by Ministries such as Health; Culture, Youth and Sport; Gender, Social Welfare and Religious Affairs; Education and Information.

- Review and implement laws that are supposed to protect child and adolescent rights taking into consideration the customs practiced by chiefs and traditional leaders and availing of opportunities for legal and social protection against forced marriage and sexual exploitation.

- Mobilize community leaders to lead the fight against adolescent pregnancy, ensuring their proper enlightenment and provision of appropriate tools.

- Campaign for girls' education and increase retention in primary and secondary school with the promotion of appropriate and sensitive sex education.

- Reduce all forms of gender base violence, encourage community protection committees to stop child marriage, develop a reporting system led by community leaders and supported by governmental and non-governmental organizations.

- Mobilize activities such as marketing and productive skills to support adolescents, addressing their specific needs (jobs, shelter, cloth, sanitary pads, and food), and ensure gender equity.

- Encourage promotion of programmes that target vulnerable groups such as families living on the street, or in internal displacement camps, and refugees.

- Establishing adolescent-friendly health services and integrating them into the primary health care system and introduce contraceptive and counselling services.

- Give extra support to adolescent mothers living with HIV and their babies. ${ }^{[23]}$

- Encourage conducting qualitative and quantitative studies on areas of adolescent health and wellbeing.

\section{References}

1. WHO https://www.who.int/southeastasia/healthtopics/adolescent-health

2. WHO 2020, Fact sheet - Adolescent pregnancy. https://www.who.int/news-room/fact-sheets/ detail/adolescent-pregnancy

3. Kassa GM, Arowojolu AO, Odukogbe AA, Yalew AW. Prevalence and determinants of adolescent pregnancy in Africa: a systematic review and metaanalysis. Reproductive Health. 2018 Dec;15(1):1-7.

4. Kane S, Miedema E, Dieleman M, Broerse J. "You have a child who will call you "mama": understanding adolescent pregnancy in South Sudan. Global Health Action. 2019 Jan 1;12(1):1553282.

5. Vincent G, Alemu FM. Factors contributing to, and effects of, teenage pregnancy in Juba. South Sudan Medical Journal. 2016 Jun 7;9(2):28-31.

6. Buchanan E. 'Born to be Married': Addressing child, early and forced marriage in Nyal, South Sudan. https://www.oxfam.org/en/research/bornbe-married-addressing-child-early-and-forcedmarriage-nyal-south-sudan

7. Jay H, Lee-Koo K. Raising Their Voices: Adolescent Girls in South Sudan's Protracted Crisis. https://reliefweb.int/sites/reliefweb.int/ files/resources/voicesfromsouthsudan_may2018.pdf

8. Manzi F, Ogwang J, Akankwatsa A, Wokali OC, Obba F, Bumba A, Nekaka R, Gavamukulya Y. Factors associated with teenage pregnancy and its effects in Kibuku Town Council, Kibuku District, Eastern Uganda: A cross sectional study. https:// www.iomcworld.org/abstract/factors-associatedwith-teenage-pregnancy-and-its-effects-inkibuku-town-council-kibuku-district-easternuganda-a-cross--47197.html.

9. Ochen AM, Chi PC, Lawoko S. Predictors of teenage pregnancy among girls aged 13-19 years in Uganda: a community based case-control study. BMC pregnancy and childbirth. 2019 Dec;19(1):1-4.

10. Austrian K, Soler-Hampejsek E, Kangwana B, Maddox N, Wado YD, Abuya B, Shah V, Maluccio JA. Adolescent Girls Initiative-Kenya: Endline evaluation report. https://knowledgecommons. popcouncil.org/departments_sbsr-pgy/998/

11. Lin WH, Liu CH, Yi CC. Exposure to sexually explicit media in early adolescence is related to risky sexual behavior in emerging adulthood. PloS one. 2020 Apr 10;15(4):e0230242. 
12. Subhanie N, Azlina TE. A review of social acceptance, psychosocial implications and coping mechanisms of teenage mothers. Available at:: http://myjms.mohe.gov.my/index.php/ijssr/ article/view/8284.

13. World Health Organization. Preventing early pregnancy and poor reproductive outcomes among adolescents in developing countries. WHO 2011https://apps.who.int/iris/bitstream/ handle/10665/44691/9789241502214_eng.

14. Turuk M. Applicability of Customary and Statutory Law in South Sudan: A Jurisprudential Perspective. Available at SSRN 3859750. 2021 Jun 3 .

15. Xu T, Tomokawa S, Gregorio Jr ER, Mannava P, Nagai M, Sobel H. School-based interventions to promote adolescent health: A systematic review in low-and middle-income countries of WHO Western Pacific Region. PloS one. 2020 Mar 5;15(3):e0230046.

16. Chandra-Mouli V, McCarraher DR, Phillips SJ, Williamson NE, Hainsworth G. Contraception for adolescents in low and middle income countries: needs, barriers, and access. Reproductive health. 2014 Dec;11(1):1-8.

17. Silumbwe A, Nkole T, Munakampe MN, Cordero JP, Milford C, Zulu JM, Steyn PS. Facilitating community participation in family planning and contraceptive services provision and uptake: community and health provider perspectives. Reproductive Health. 2020 Dec;17(1):1-1.

18. Awang H, Ab Rahman A, Sukeri S, Hashim N, Nik Abdul Rashid NR. Adolescent-friendly health services in primary healthcare facilities in Malaysia and its correlation with adolescent satisfaction level. International Journal of Adolescence and Youth. 2020 Dec 31;25(1):551-61.

19. Darroch JE, Woog V, Bankole A, Ashford LS, Points K. Costs and benefits of meeting the contraceptive needs of adolescents. Guttmacher Institute. 2016 May. https:/www.guttmacher. org/sites/default/files/report_pdf/adding-it-upadolescents-report.pdf

20. World Health Organization. Preventing early pregnancy and poor reproductive outcomes among adolescents in developing countries: What the evidence says. World Health Organization; 2012. http://whqlibdoc.who.int/hq/2012/ WHO_FWC_MCA_12_02.pdf.

21. Chandra-Mouli V, Camacho AV, Michaud PA. WHO guidelines on preventing early pregnancy and poor reproductive outcomes among adolescents in developing countries. Journal of adolescent health. 2013 May 1;52(5):517-22.

22. Public Health England, 2018, Teenage Pregnancy Prevention Framework Supporting young people to prevent unplanned pregnancy and develop healthy relationships. https://assets.publishing. service.gov.uk/government/uploads/system/ uploads/attachment_data/file/836597/Teenage_ Pregnancy_Prevention_Framework.pdf.

23. Elona Toska et al. Adolescent mothers affected by HIV and their children: A scoping review of evidence and experiences from sub-Saharan Africa https://doi.org/10.1080/17441692.2020.1775867 